\title{
Some observations on workers exposed to methylene chloride
}

\author{
NICOLA CHERRY ${ }^{1}$ HELEN VENABLES, ${ }^{1} \mathrm{H}$ A WALDRON, ${ }^{1}$ AND G G WELLS ${ }^{2}$ \\ From the TUC Centenary Institute of Occupational Health, ${ }^{1}$ London School of Hygiene and Tropical \\ Medicine, London WC1E 7HT, and Employment Medical Advisory Service, ${ }^{2}$ Chelmsford, Essex, UK
}

\begin{abstract}
An excess of self-reported neurological symptoms was found when a group of 46 men exposed to methylene chloride at concentrations below $100 \mathrm{ppm}$ was compared with a non-exposed referent group. A follow-up study was then carried out to see whether there was any evidence of neuropsychological damage in the exposed men. Twenty-nine of the original group participated in this study. Age-matched controls were selected from among men working on a similar process but with no exposure to solvents. Each man in the study had a clinical examination; motor conduction velocities were measured in the ulnar and median nerves; an ECG was taken and a psychological test battery designed to detect minimal brain damage was administered. No evidence was found of longterm damage that could be attributed to exposure to methylene chloride.
\end{abstract}

Methylene chloride is rapidly metabolised and excreted and little evidence has been presented of long-term damage attributed to the solvent. In a recent study in East Anglia, however, men exposed to several solvents, predominantly methylene chloride, expressed concern that long-term exposure to the solvent might be affecting their health. This concern arose from case reports of acute cardiac episodes $^{1}$ after high exposure. Methylene chloride is rapidly metabolised to carbon monoxide, ${ }^{2}$ but since the carbon monoxide combines rapidly with haemoglobin to form carboxyhaemoglobin it has no direct toxic effect.

The men expressing the concern had been recruited for a study of the interactive effects on performance of shift work and exposure to solvents, but they were also asked to complete a questionnaire about symptoms relating to heart disease and to the neurological and affective changes that have been attributed to long-term exposure to solvents. ${ }^{3}$

The results of the shift work study will be reported elsewhere; this paper considers the symptoms reported and the action subsequently taken to investigate whether methylene chloride was affecting the health of the men volunteering for the study.

\section{Study sample}

Forty-six men working in a factory making acetate

Received 19 May 1981

Accepted 30 June 1981 film were recruited for the study of interactive effects on performance. The men were exposed to a mixture of methylene chloride and methanol (9:1), atmospheric concentrations of methylene chloride being in the range $75-100 \mathrm{ppm}$.

The men worked a rapidly rotating shift (0600$1400 ; 1400-2200 ; 2200-0600$ ) with at most three days on each shift. As there was scant information on the effects of this shift pattern on the performance measures being used, a small referent group of 12 men following the same shift pattern but without exposure to solvents was also studied. The number of referents was necessarily small because most of the factory worked a standard two-shift system.

All the men were volunteers, and the response to the initial request (by the safety officer) produced a sample of adequate size from among the target population of 76. As a result, no attempt was made to persuade those who did not volunteer, and the study group cannot be taken as necessarily representative of the whole work force.

\section{CARDIAC SYMPTOMS}

The men were asked whether they had ever suffered from three symptoms; pain in the arms, chest pain sitting or lying, or chest pain when walking or hurrying. Six of the exposed men (five from within a group of 29 with ten or more years' exposure) reported at least one symptom that might be associated with heart disease. None of these symptoms was reported by any of the men in the referent group. 
Table 1 Proportion of exposed and referents with recent symptoms in the initial study

\begin{tabular}{|c|c|c|c|c|c|c|}
\hline & \multicolumn{5}{|c|}{ No of symptoms reported } & \multirow[t]{2}{*}{$\chi_{1}^{2}($ assuming linear trend $)$} \\
\hline & 0 & 1 & 2 & 3 or more & Total & \\
\hline \multicolumn{7}{|c|}{ Neurological symptoms } \\
\hline Exposed & 26 & 8 & 9 & 3 & 46 & \multirow[t]{2}{*}{$5.41 \mathrm{p}<0.02$} \\
\hline Referent & 11 & 1 & 0 & 0 & 12 & \\
\hline \multicolumn{7}{|c|}{ Affective symptoms } \\
\hline Exposed & 28 & 6 & 7 & 5 & 46 & \multirow[t]{2}{*}{$1 \cdot 72 \mathrm{NS}$} \\
\hline Referent & 9 & 2 & 1 & 0 & 12 & \\
\hline \multicolumn{7}{|c|}{ Stomach ache } \\
\hline Exposed & 40 & 6 & - & - & 46 & \multirow[t]{2}{*}{$0.11 \mathrm{NS}$} \\
\hline Referent & 10 & 2 & - & - & 12 & \\
\hline
\end{tabular}

RECENT NEUROLOGICAL AND AFFECTIVE SYMPTOMS

The men were asked whether, during the past 12 months, they had experienced any of a list of nine symptoms. Five of these were chosen to reflect possible neurological disorders (frequent headaches, dizziness, loss of balance, difficulty in remembering things, and numbness and tingling in the hands or feet) and three to reflect a change in mood or affect (irritability, depression, or tiredness); the remaining symptom (stomach ache) was included as a check on a general tendency for the men under study to overreport.

When the symptoms reported by the 46 exposed men were compared with those of the 12 men without exposure, an excess of recent symptoms was found only in the group of neurological complaints.

Twenty of the 46 men in the exposed group reported having experienced at least one of these five symptoms during the previous 12 months but only one man in the referent group (table 1). There was no excess in the group of affective symptoms or in reports of stomach ache.

Twenty-nine of the men (mean age 48) had been exposed to solvents for ten years or more at this factory and 17 (mean age 36) for a shorter period. The referent group, although slightly older (mean age 39) than the group exposed for under 10 years, reported fewer neurological symptoms (fig). More men in the group with longer exposure tended to report at least one neurological symptom.

\section{Interpretation of the initial study}

It appeared from this initial study that the men exposed to solvents complained of more neurological symptoms than the men in the referent group. There were several possible explanations for this. Firstly, it might be that the symptoms were quite unrelated to exposure and that the differences arose from inadequate matching in the referent group. Secondly, it might be that the symptoms were related to exposure but had occurred only after the intermittent high exposures that workers at the factory still occasionally experience. If this were so the reported neurological symptoms need not reflect any long-term damage. A third possibility was that the symptoms reflected neurological damage that might be related to long-term exposure to solvents close to permitted concentrations. To investigate these pos-

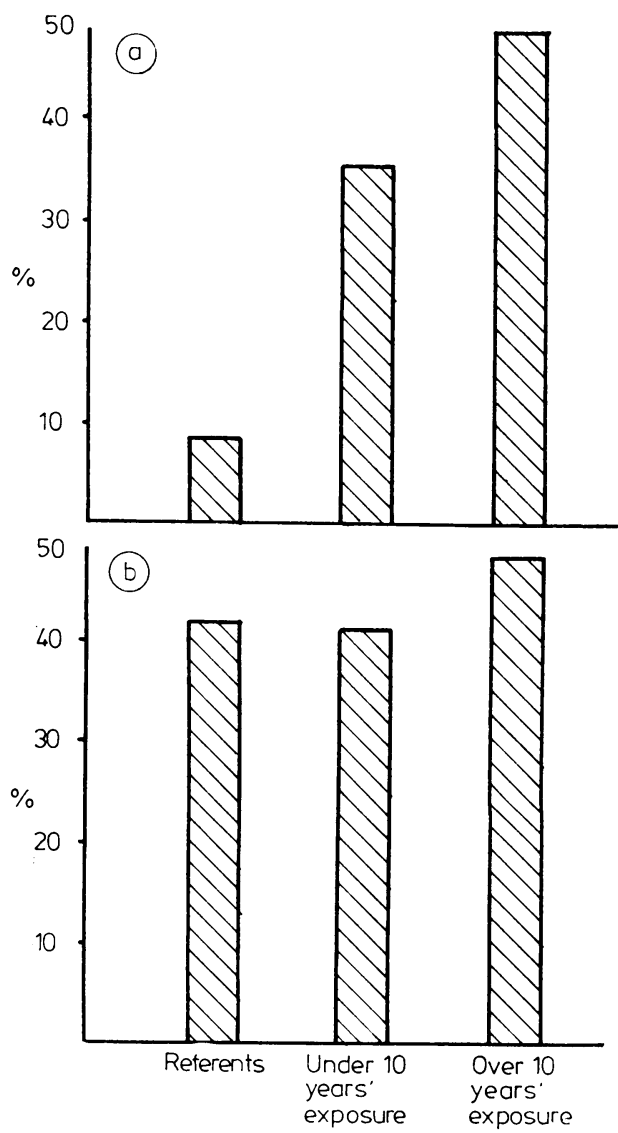

Proportion of solvent workers and referents reporting one or more neurological $(A)$ or non-neurological $(B)$ symptoms in the initial study. 
sibilities, arrangements were made to recruit an adequate referent group, to ask the exposed men in the initial study about the circumstances in which their symptoms occurred, and to carry out a series of tests and examinations to see whether subjective symptoms were accompanied by measurable neurological and performance deficits.

\section{Follow-up study}

\section{EXPOSED GROUP}

Only 29 of the 46 men in the exposed group took part in the follow-up study; of the 17 not included, some had been made redundant as a result of the economic recession and others, moved to jobs within the factory which did not entail exposure to solvents, did not wish to take part. Information collected at the initial contact, however, allows us to make some comparisons between the participators and non-participators.

The men who did not take part in the follow-up study were similar in age to those who did ( 44.2 years compared with 43.6 ) and had a similar pattern of symptoms. The follow-up sample had complained of slightly more affective symptoms $(41.4 \%$ compared with $35.3 \%$ ) and slightly fewer neurological ones $(41.4 \%$ compared with $47 \cdot 1 \%)$. None of these differences suggested important bias in the follow-up group.

Each of the exposed men was invited to attend the medical centre on the factory site. They were questioned again about their symptoms, and although this close questioning elicited many further symptoms, particularly about tiredness and memory, very few (under $10 \%$ ) of the symptoms were attributed by the men themselves to incidents of high exposure. Investigations for chronic effects were then carried out.

\section{REFERENT GROUP}

The need for an adequate comparison group was met by recruiting 29 men, individually age matched to within three years, from a factory (within the same parent company) that carried out an almost identical process but one that did not entail exposure to solvents. The men worked a rapidly rotating shift pattern and were thus comparable with the exposed men in this respect. The comparison group worked, however, in South-west Scotland, an area with an incidence of deaths from heart disease higher than East Anglia (1·8:1 in men aged 45-64 using the 1978 Registrar General's data).

The men were asked to complete the symptom questionnaire used in the initial study of the solvent workers and, within a few days, to undergo the same series of tests and examinations.
INVESTIGATIONS CARRIED OUT AT BOTH FACTORIES

Each man underwent a full neurological examination, an ECG was taken, and motor nerve conduction velocities in the ulnar and median nerves were measured. Several psychological tests thought to be sensitive to minimal organic brain damage were then administered. Six tests were used: a dotting test (to measure motor speed and accuracy); the two-part trail-making test devised by Reitan (Trail Making Test: manual for administration, scoring, and interpretation, available from the author, 1338 Edison Street, Arizona 85719 USA); a visual search task adapted from the one described by Goldstein et $a l^{5}$; the block design task from the Wechsler Adult Intelligence $\mathrm{Scale}^{6}$; a reading test (Nelson Adult Reading Test: test manual available from National Hospital for Nervous Diseases, London); and a memory test. ${ }^{7}$ The complete examination took about 90 minutes. At the end of the session the man was asked for permission to inform his medical practitioner of the outcome.

\section{Results of the follow-up study}

Clinical examination-There was no difference of any note between the two groups of men. None had any signs of serious neurological disease, but four of the subjects and three of the referents had minimal loss of vibration in the toes.

$E C G$-ECG tracings were taken for all 58 men in the exposed and referent groups. Abnormalities were found for seven of the men-two in the exposed and five in the referent group. Only one of the abnormalities (left bundle branch block in one of the referents) was considered to be serious. This ratio, $2 \cdot 5: 1$, is of the same order as the ratio of deaths from heart disease in the two areas, and this study provides no evidence that methylene chloride was related to cardiac abnormalities.

Neurophysiological studies - There was no evidence of slowing of motor nerve conduction velocity in either the ulnar or the median nerve in the exposed group

Table 2 Results of neurophysiological studies in exposed and referent groups; (means and standard deviations in parentheses)

\begin{tabular}{lrr}
\hline & Exposed & \multicolumn{1}{c}{ Referent } \\
\hline Ulnar nerve & & \\
Distal latency (msec) & $3 \cdot 0(0 \cdot 7)$ & $2 \cdot 9(0 \cdot 6)$ \\
Motor conduction velocity (m/s) & $60 \cdot 8(8 \cdot 0)$ & $57 \cdot 4(7 \cdot 8)$ \\
Amplitude (mV) & $8 \cdot 3(5 \cdot 0)$ & $6 \cdot 8(3.9)$ \\
Median nerve & $3 \cdot 5(0 \cdot 5)$ & $3.4(0 \cdot 5)$ \\
Distal latency (msec) & $56 \cdot 9(5 \cdot 8)$ & $58 \cdot 9(6 \cdot 0)$ \\
Motor conduction velocity (m/s) & $9 \cdot 0(5 \cdot 1)$ & $8 \cdot 2(3 \cdot 3)$ \\
Amplitude (mV) & & \\
\hline
\end{tabular}


Table 3 Scores on six performance tests in exposed and referent groups; (means and standard deviations in parentheses)

\begin{tabular}{|c|c|c|c|}
\hline & Exposed & Referent & $P<$ \\
\hline \multicolumn{4}{|l|}{ Trail making* } \\
\hline $\begin{array}{l}\text { Total time (seconds) } \\
\text { Motor task** }\end{array}$ & $87 \cdot 5(22 \cdot 2)$ & $103 \cdot 9(27 \cdot 2)$ & 0.01 \\
\hline No of dots made in 10 seconds & $36.7(9.4)$ & $41 \cdot 3 \quad(7.4)$ & 0.05 \\
\hline Block design** & & & \\
\hline Total score & $37 \cdot 4(8 \cdot 2)$ & $33.4 \quad(6 \cdot 8)$ & 0.05 \\
\hline $\begin{array}{l}\text { Nelson Adult Reading Test** } \\
\text { No of words correct }\end{array}$ & $22.6(8.5)$ & $24.5(9 \cdot 1)$ & NS \\
\hline Buschke memory test ${ }^{* *}$ & & & \\
\hline Total recall after 5 trials & $15 \cdot 0(2 \cdot 8)$ & $13.9(2.9)$ & NS \\
\hline \multicolumn{4}{|l|}{ Visual search* } \\
\hline Total time for 10 trials (seconds) & $180 \cdot 0(69 \cdot 2)$ & $212 \cdot 4(84 \cdot 6)$ & NS \\
\hline
\end{tabular}

* Low score indicates good function.

**High score indicates good function.

(table 2). The two groups of men were virtually identical on every measure taken.

Psychological tests-The exposed men were at a disadvantage only on the task requiring a fairly coarse motor activity (dotting rapidly on either side of two parallel lines $10.5 \mathrm{~cm}$ apart) where they made (on average) $10 \%$ fewer dots than the referent group in the ten seconds given for the tests (table 3 ). In two of the tests the block design task from the WAIS and the trail-making test, the group exposed to solvents did significantly better than the age-matched referent group. Both these tests are related to overall intelligence, and this difference between the groups might suggest that the exposed men were, before exposure, rather more able than the referents. The test of reading ability, designed to reflect premorbid educational level, was included to investigate how well the groups were matched intellectually, and interestingly the referent group did rather better in this test. There was no difference between the scores on the visual search-task, nor was any difference found between the groups on any of the measures derived from a complex memory task; inspection of the scores for these tests gave no intimation of a tendency for the exposed men to do less well. With this set of psycho- logical tests, no detrimental effects could be found that might be attributable to occupational exposure to solvents.

\section{SYMPTOMS}

Both groups of men completed a questionnaire about long-term (largely cardiac) and recent symptoms. The exposed men had filled in these questionnaires as part of the initial study, and their recent symptoms are compared with those reported by the agematched referent group (table 4). Five men in each of the groups complained of stomach ache, the symptom included as a check on over-reporting, but there was a slight tendency for the exposed men to complain of more neurological symptoms than the non-exposed group. This difference was in the direction anticipated from the results of the initial study (table 1), but the use of an adequate referent group has reduced the difference in reported neurological symptoms to an excess that, in groups of this size, might well have arisen by chance. There is no evidence from this study of a true difference in the incidence of symptoms in men exposed to methylene chloride and men of the same age who have not had this exposure.

\section{Discussion}

We have reported the steps taken to assess objectively an apparent over-reporting of neurological symptoms in a group of men exposed to methylene chloride. No evidence was found of long-term damage attributable to this solvent, and although negative findings of this sort cannot be used to show that the solvent is completely safe, the results may give some reassurance to those whose work entails repeated exposure.

The positive lessons to be learnt from the study are largely methodological. Firstly, it underlines the need for very considerable efforts to obtain an appropriate reference group; had the more adequate referents not been examined, there would have remained at least the suspicion that the over-report-

Table 4 Proportion of exposed and referent with recent symptoms in the follow-up study

\begin{tabular}{|c|c|c|c|c|c|c|}
\hline & \multicolumn{5}{|c|}{ No of symptoms reported } & \multirow[t]{2}{*}{$x_{1}^{2}$ (assumming linear trend) } \\
\hline & 0 & 1 & 2 & 3 or more & Total & \\
\hline \multicolumn{7}{|c|}{ Neurological symptoms } \\
\hline Exposed & 17 & 4 & 6 & 2 & 29 & \multirow[t]{2}{*}{$2.00 \mathrm{NS}$} \\
\hline \multicolumn{6}{|c|}{ Affective symptoms } & \\
\hline Exposed & 17 & 4 & 6 & 2 & 29 & \multirow[t]{2}{*}{$1.24 \mathrm{NS}$} \\
\hline Referent & 21 & 3 & 4 & 1 & 29 & \\
\hline \multicolumn{7}{|c|}{ Stomach ache } \\
\hline Exposed & 24 & 5 & - & - & 29 & \multirow[t]{2}{*}{$0 \cdot 12 \mathrm{NS}$} \\
\hline Referent & 24 & 5 & - & - & 29 & \\
\hline
\end{tabular}


ing of neurological symptoms in the initial study was due to solvent exposure. Secondly, the study demonstrates that an objective investigation of neuropsychological effects of solvents can be carried out rapidly and in a way that is acceptable to management, to the men exposed to the solvent, and to their own medical practitioners. Many solvents are now under suspicion of causing neuropsychological damage after long-term exposure, and the approach used in the present study does appear to be useful in investigating objectively the feelings of ill health often attributed by workers to their exposure to industrial solvents.

We are most grateful to the management and men at the two factories who did all that was possible to make this study a success; we would particularly like to thank Mr Alan Scott and Mr Alan Smith the respective safety officers for their efforts on our behalf. It is a pleasure to acknowledge the help that $\mathrm{Mr} \mathbf{P}$ Jamie gave us in advising on appropriate tests to include in the psychological test battery. We are also happy to acknowledge the help given by the Colt Foundation in supporting this research.

\section{References}

${ }^{1}$ Stewart RD, Hake CL. Paint-remover hazard. JAMA 1976; 235:398-401.

${ }^{2}$ Stewart RD, Fisher TN, Hosko MJ, Peterson JE, Baretta ED, Dodd HC. Carboxyhaemoglobin elevation after exposure to methylene chloride. Science 1972;176:295-6.

${ }^{3}$ Hogstedt C, Hane M, Axelson O. Diagnostic and health care aspects of workers exposed to solvents. In: Zenz C, ed. Developments in occupational medicine. Chicago: Year Book Medical Publishers, 1980:249-58.

${ }^{4}$ Goldstein G, Welch RB, Rennick RM, Shelley CH. The validity of a visual searching task as an indicator of brain damage. J Consult Clin Psychol 1973;3:434-7.

${ }^{5}$ Saville P. A British supplement to the manual of the Weschler Adult Intelligence Scale. Windsor NFER Publishing Company Limited, 1971.

${ }^{6}$ Buschke H. Selective reminding for analysis of memory and learning. Journal of Verbal Learning and Verbal Behaviour 1973;12:543-50. 